\title{
Optimasi Proses Pemesanan Spare Part Dengan Menggunakan Metode Value Stream Mapping
}

\author{
D. E. Prasetyo
}

\begin{abstract}
Abstrak - Penelitian ini bertujuan untuk meningkatkan pelayanan proses pemesanan spare part agar tercipta waktu tunngu yang lebih singkat. Lean adalah metode yang dapat meminimalkan pemborosan atau waste pada proses produksi atau proses pelayanan. Dalam penelitian ini menggunakan metode value stream mapping untuk mengoptimalkan waktu proses pemesanan spare part di PT. Prima Wahana Automobil. Optimasi proses pelayanan dilakukan dengan minimasi waste dengan tools VALSAT yaitu Process Activity Mapping. Penelitian ini menghasilkan value ratio sebesar $66,1 \%$. Value ratio merupakan perbandingan antara aktivitas yang memiliki nilai tambah dengan keseluruhan aktivitas. Sedangan persentase kegiatan yang tidak memilki nilai tambah sebesar 33,1\%. Dan kegiatan yang tidak memiliki nilai tapi dibutuhkan sebesar 0,8\%. Usulan perbaikan dilakukan dengan mengurangi aktivitas yang tidak memiliki nilai tambah.
\end{abstract}

Kata Kunci- Produksi ramping, pemetaan aliran nilai, alat analisis aliran nilai

Abstract - This study aims to improve the service process for ordering spareparts so as to create a shorter lead time. Lean is a method that can minimize waste or waste in the production process or service process. In this study using the value stream mapping method to optimize the order processing time of spare parts at PT. Prima Wahana Automobil. The optimization of the service process is done by minimizing waste with VALSAT tools, namely Process Activity Mapping. This study produced a value ratio of $66.1 \%$. Value ratio is a comparison between activities that have added value to the overall activity. While the percentage of activities that do not have added value is $33.1 \%$. And activities that have no value but are needed at $0.8 \%$. Proposed improvements are made by reducing activities that have no added value.

Keywords - lean manufacturing, value stream mapping, waste, value stream analysis tools

\section{PENDAHULUAN}

K epuasan pelanggan merupakan kunci utama dalam mencapai sebuah kesuksesan usaha. Baik usaha dalam bidang produksi atau jasa. Kepuasan pelanggan diraih, apabila sudah tercapainya atau terlampauinya kebutuhan dan harapan para pelanggan. Untuk menjamin kepuasan pelanggan, dari setiap rangkaian proses pelayanan tidak diharapkan terjadi kesalahan atau menimbulkan halhal yang bisa mengecewakan pelanggan. Fokus lean manufacturing adalah peningkatan nilai. Setiap langkah atau proses yang memberikan nilai tambah pada produk akhir akan dipertahankan. Sebaliknya, segala sesuatu yang tidak memberikan nilai tambah atau limbah akan dihilangkan atau dieliminasi.

Mengukur nilai tambah adalah langkah pertama dalam lean production atau lean manufacturing. Setelah itu, barulah melakukan usaha untuk menghilangkan limbah. Lean manufacturing menyediakan seperangkat standar solusi untuk

Dedi Eko Prasetyo, Mahasiswa Program Studi Teknik Industri, Universitas Indraprasta PGRI, Jakarta (prasetyodedi91@gmail.com) masalah umum dan mengoptimalkan proses di seluruh rantai nilai, tetapi tidak memiliki struktur organisasi, alat-alat analisis, serta kontrol kualitas [1].

PT. Prima Wahana Automobil merupakan perusahaan otomotif yang bergerak dalam bidang purna jual kendaraan bermotor yang terfokus pada satu merk kendaraan yaitu wuling. Pada departemen aftersales menawarkan jasa service dan penjualan spare part rekomendasi dan standard merk wuling. Salah satu pelayanan yang sering menjadi sorotan adalah layanan proses pengadaan spare part yang tidak tersedia di dealer. Proses order spare part ini memerlukan beberapa proses, tidak jarang proses ini membutuhkan waktu yang lama dan melebihi waktu estimasi yang diberikan ke pelanggan. Ketidaksesuaian ini yang menimbulkan keluhan dari pelanggan, karena lamanya proses dan ketidaknormalan waktu tunggu. Lamanya proses menunggu disebabkan karena kurang optimalnya tahapan proses pelayanan order spare part. Terdapat aktivitas atau tahapan pelayanan yang menimbulkan waste atau pemborosan proses sehingga 
menimbulkkan waktu tunggu yang berlebih.

Untuk menghilangkan pemborosan tersebut dilakukan dengan metode lean manufacturing. Value stream mapping adalah salah satu tool dalam lean manufacturing yang memetakkan aliran bahan baku atau material dan informasi mulai dari kedatangan, proses yang terjadi, hingga suatu produk sampai ke konsumen. Value stream mapping merupakan peralatan visual yang digunakan untuk menemukan dan mengeliminasi waste [2]. Value stream mapping adalah tool grafik dalam lean manufacturing yang membantu melihat flow material dan informasi mulai dari raw material sampai diantar ke customer. Oleh karena itu VSM dapat membantu menemukan waste yang muncul dalam proses pelayanan order spare part.

Di dalam penelitian ini dilakukan karena adanya perbedaan waktu tunggu yang diharapkan oleh customer berdasarkan masing-masing kategori, dan waktu tunggu aktual kedatangan part yang dipesan. Terdapat selisih waktu tunggu yang diaharapkan customer dengan waktu tunggu aktual di lapangan. Hal ini yang menyebabkan munculnya keluhan customer tentang pelayanan proses pemesanan part yang tidak sesuai dengan yang diharapkan. Dengan uraian tabel tersebut peneliti termotivasi untuk melakukan penelitian demi tercapainya proses order part yang lebih singkat sehingga proses pelayanan sesuai dengan harapan pelanggan untuk menghasilan output dan kepuasan pelanggan yang maksimal.

\section{METODE DAN PROSEDUR}

Desain penelitian dilakukan untuk membandingkan waktu proses order spare part sebelum dilakukan optimasi dengan waktu proses order spare part setelah optimasi tahapan proses. Penelitian ini menggunakan metode value stream mapping untuk menggambarkan kegiatan-kegiatan yang sedang berjalan di perusahaan. Penelitian diawali dengan melakukan pengamatan terhadap proses yang berjalan dan wawancara dengan pihakpihak yang terkait sehingga penggambaran value stream mapping yang dilakukan sesuai dengan kondisi aktual yang ada. Hasil penggambaran dari value stream mapping tersebut akan dianalisa berdasarkan tipe waste yang ada pada metode lean manufacturing, dari masing-masing kegiatan tersebut.
Pada tahap awal penelitian dilakukan pengumpulan data dengan cara survey atau tinjauan langsung ke lapangan. Dilanjutkan dengan interview atau wawancara dengan bagian terkait tentang proses pelayanan atau waktu tahapan proses order spare part. Pencatatan waktu proses di setiap tahapan pelayanan dengan menggunkaan jam henti atau stopwatch. Proses pengambilan data dilakukan secara langsung di lapangan kerja dengan mengikuti urutan alur proses.

Proses pengolahan data awal, dilakukan dengan cara mapping atau penggambaran alur proses pelayanan dalam bentuk current state map. Setelah itu dilakukan identifikasi waste dengan konsep waste assessment model. Dari hasil pembobotan waste, akan dapat digunakan untuk pemilihan tools yang digunakan pada VALSAT. Dengan tools yang dipilih, akan digunakan untuk membantu analisis dan minimasi waste pada proses pelayanan untuk proses optimasi. Survey dilakukan terhadap karyawan terkait yang melaksankan langsung proses pelayanan spare part sebanyak 5 responden. Dalam proses pembobotan waste menggunakan teori indicator dengan melakukan perhitungan tabulasi menggunakan tabel keterkaitan antar waste seven waste relationship.

\section{III.HASIL DAN PEMBAHASAN}

Tahapan awal dari pengolahan data adalah dengan menggambarkan kondisi aktual di lapangan dalam setiap aliran proses yang dilakukan dalam bentuk current state map atau pemetaan proses awal sebelum adanya usulan. Dan pada tahap ini dapat dilakukan analisis pemborosan-pemborosan yang terjadi ketika proses berlangsung.

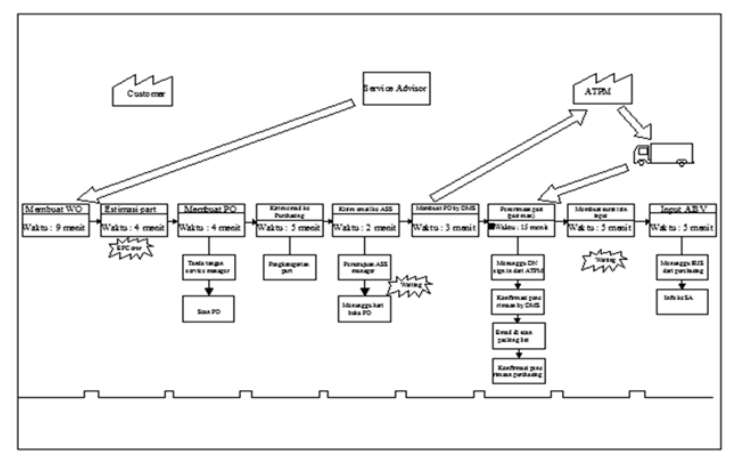

Gambar 1. Current state map

Tahapan selanjutnya adalah melakukan identifikasi waste yang muncul dengan konsep waste assessment model 
Setelah dilakukan mapping dengan process

Tabel 1. Hasil perhitungan waste assessment

\begin{tabular}{lccccccc}
\hline & $\mathrm{O}$ & $\mathrm{I}$ & $\mathrm{D}$ & $\mathrm{M}$ & $\mathrm{T}$ & $\mathrm{P}$ & $\mathrm{W}$ \\
\hline Skor (Yj) & 0.31 & 0.28 & 0.29 & 0.24 & 0.24 & 0.32 & 0.27 \\
Pj Faktor & 310.29 & 279.41 & 261.76 & 379.41 & 257.35 & 252.94 & 322.06 \\
$\begin{array}{l}\text { Hasil Akhir } \\
\text { (Yj Final) }\end{array}$ & 96.61 & 77.33 & 75.42 & 92.16 & 61.68 & 80.51 & 86.71 \\
$\begin{array}{l}\text { Hasil Akhir } \\
(\%)\end{array}$ & 16.94 & 13.56 & 13.22 & 16.16 & 10.81 & 14.11 & 15.20 \\
\hline Ranking & 1 & 5 & 6 & 2 & 7 & 4 & 3 \\
\hline
\end{tabular}

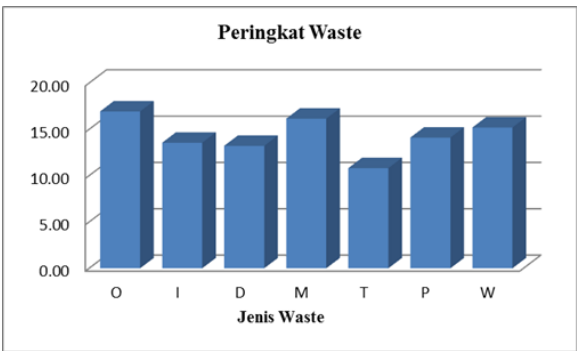

Gambar 2. Peringkat waste

Hasil dari pembobotan waste diketahui bahwa peringkat pertama yaitu over production $(\mathrm{O})$ dengan persentase 16,94\%. Artinya menunjukkan bahwa waste over production (O) sangat berpengaruh terhadap waste lainnya. Berdasarkan hasil waste assessment model, maka nilai tersebut dapat digunakan untuk pemilihan tools pada VALSAT. Berikut tabel penentuan tools:

Tabel 2. Hasil pembobotan VALSAT

\begin{tabular}{|c|c|c|c|c|c|c|c|c|}
\hline \multirow[b]{2}{*}{ Waste } & \multirow{2}{*}{ Weight } & \multicolumn{7}{|c|}{ Mapping Tools } \\
\hline & & PAM & SCRM & PVF & QFM & DAM & DPA & PS \\
\hline $\begin{array}{l}\text { Over Production } \\
\text { Unnecessary }\end{array}$ & 16.94 & 16.94 & 50.81 & 0.00 & 16.94 & 50.81 & 50.81 & 0.00 \\
\hline Inventory & 13.56 & 40.67 & 122.02 & 40.67 & 0.00 & | 22.02 & 40.67 & 13.56 \\
\hline $\begin{array}{l}\text { Defect/ Reject } \\
\text { Unnecessary }\end{array}$ & 13.22 & 13.22 & 0.00 & 0.00 & 0.00 & $\lfloor 19.00$ & 0.00 & 0.00 \\
\hline $\begin{array}{l}\text { Motion } \\
\text { Excessive }\end{array}$ & 16.16 & 145.40 & 16.16 & 0.00 & 0.00 & 0.00 & 0.00 & 0.00 \\
\hline $\begin{array}{l}\text { Transportation } \\
\text { Inapprooriate }\end{array}$ & 10.81 & 97.32 & 0.00 & 0.00 & 0.00 & 0.00 & 0.00 & 10.81 \\
\hline & & & & 2.34 & 14.11 & & & $0 .($ \\
\hline Waiting / Idle & 15.20 & 136.81 & 136.81 & 15.20 & 0.00 & 45.60 & 45.60 & 0.00 \\
\hline Total & & 577.39 & 325.80 & 98.22 & 31.05 & 337.43 & $\mathbf{1 5 1 . 2 0}$ & 24.37 \\
\hline
\end{tabular}

Berdasarkan peringkat mapping tools dapat diketahui bahwa tools yang digunakan adalah Process Activity Mapping (PAM). Berikut tahapan proses pembuatannya:

a. Mencatat semua aktivitas proses pelayanan

b. Mengklasifikasikan aktivitas tersebut ke dalam aktivitas operation $(\mathrm{O})$, transport $(\mathrm{T})$, inspection (I), storage (S), dan delay (D).

c. Menambahkan informasi untuk analisis selajutnya.

d. Menganalisis aktivitas yang tergolong value added (VA), non value added (NVA), dan non value added but necessary (NNVA) activity mapping, maka dibuatkan tabulasi ringkasan perhitungan dan persentase sebagai berikut:

Tabel 3. Proses Activity Mapping

\begin{tabular}{|c|c|c|c|c|c|c|c|c|}
\hline \multirow{2}{*}{ No. } & \multirow{2}{*}{ Kegiatan } & \multirow{2}{*}{ Waktu } & \multicolumn{5}{|c|}{ Aktivitas } & \multirow{2}{*}{$\begin{array}{l}\text { VA/NVA/ } \\
\text { NNVA }\end{array}$} \\
\hline & & & $\mathbf{O}$ & $\mathbf{T}$ & $\mathbf{I}$ & $\mathbf{S}$ & D & \\
\hline 1 & $\begin{array}{l}\text { Membuat WO } \\
\text { (Work Order) }\end{array}$ & 9 & $\mathrm{O}$ & & & & & VA \\
\hline 2 & $\begin{array}{l}\text { Membuat } \\
\text { estimasi part }\end{array}$ & 4 & $\mathrm{O}$ & & & & & VA \\
\hline 3 & Membuat PO & 4 & $\mathrm{O}$ & & & & & VA \\
\hline 4 & $\begin{array}{l}\text { Tanda tangan } \\
\text { service manager }\end{array}$ & 2 & $\mathrm{O}$ & & & & & NNVA \\
\hline 5 & Scan PO & 5 & $\mathrm{O}$ & & & & & NVA \\
\hline 6 & $\begin{array}{l}\text { Mengirim email } \\
\text { ke purchasing } \\
\text { part }\end{array}$ & 5 & $\mathrm{O}$ & & & & & NNVA \\
\hline 7 & $\begin{array}{l}\text { Analisa data } \\
\text { (pengkategorian } \\
\text { part : slow } \\
\text { moving or fast } \\
\text { moving) }\end{array}$ & 1 & & & I & & & NNVA \\
\hline 8 & $\begin{array}{l}\text { Mengirim email } \\
\text { ke ASS manager }\end{array}$ & 2 & $\mathrm{O}$ & & & & & NVA \\
\hline 9 & $\begin{array}{l}\text { Persetujuan ASS } \\
\text { manager }\end{array}$ & 1 & & & & & $\mathrm{D}$ & NNVA \\
\hline 10 & $\begin{array}{l}\text { Menunggu hari } \\
\text { buka PO }\end{array}$ & 2 hari & & & & & $\mathrm{D}$ & VA \\
\hline 11 & $\begin{array}{l}\text { Purchasing part } \\
\text { buat PO ke } \\
\text { ATPM by DMS }\end{array}$ & 3 & $\mathrm{O}$ & & & & & VA \\
\hline 12 & $\begin{array}{l}\text { Penerimaan di } \\
\text { dealer (periksa } \\
\text { kondisi dan qty } \\
\text { by packing list) }\end{array}$ & 15 & & & I & & & NNVA \\
\hline 13 & $\begin{array}{l}\text { Konfirmasi } \\
\text { penerimaan } \quad b y \\
\text { DMS }\end{array}$ & 10 & & & & & $\mathrm{D}$ & NNVA \\
\hline 14 & $\begin{array}{l}\text { Email scan } \\
\text { packing list }\end{array}$ & 5 & $\mathrm{O}$ & & & & & NVA \\
\hline 15 & $\begin{array}{l}\text { Konfirmasi } \\
\text { penerimaan } \\
\text { purchasing part }\end{array}$ & 3 & & & & & $\mathrm{D}$ & NVA \\
\hline 16 & $\begin{array}{l}\text { Purchasing part } \\
\text { mengeluarkan } \\
\text { surat izin input } \\
\text { part di AISV }\end{array}$ & 5 & $\mathrm{O}$ & & & & & NVA \\
\hline 17 & $\begin{array}{l}\text { Menunggu IRIS } \\
\text { part }\end{array}$ & 1 hari & & & & & $\mathrm{D}$ & NVA \\
\hline 18 & Input ke AISV & 5 & $\mathrm{O}$ & & & & & VA \\
\hline 19 & $\begin{array}{l}\text { Info ke SA } \\
\text { (Service Advisor) }\end{array}$ & 2 & $\mathrm{O}$ & & & & & VA \\
\hline & Total & & 12 & 0 & 2 & 0 & 5 & \\
\hline
\end{tabular}

Tabel 4. Ringkasan Perhitungan dan Prosentase PAM

\begin{tabular}{|c|c|c|}
\hline Aktivitas & Jumlah & Waktu (menit) \\
\hline Operation & 12 & 51 \\
\hline Transport & 0 & 0 \\
\hline Inspection & 2 & 16 \\
\hline Storage & 0 & 0 \\
\hline Delay & 5 & 4334 \\
\hline Total & 19 & 4401 \\
\hline Kalsifikasi & Jumlah & Waktu (menit) \\
\hline $\mathrm{VA}$ & 6 & 2907 \\
\hline NVA & 7 & 1460 \\
\hline NNVA & 6 & 34 \\
\hline Total & 19 & 4401 \\
\hline \multicolumn{2}{|c|}{ Value Ratio } & $66.1 \%$ \\
\hline
\end{tabular}

Berdasarkan perhitungan diatas, diketahui bahwa hasil value ratio sebesar $66,1 \%$. Value ratio merupakan perbandingan aktivitas yang memberi nilai tambah dengan keseluruhan aktivitas. Setelah 
dilakukan proses mapping, dilakukan analisis menggunakan causes and effect diagram.

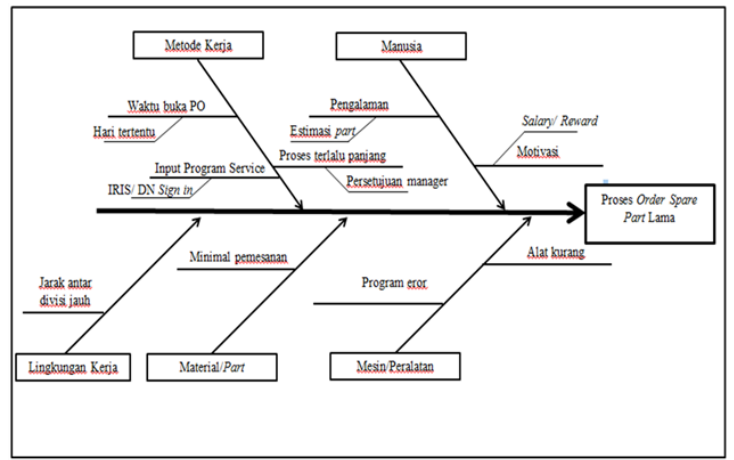

Gambar 3. Cause and effect diagram

Berikut hasil analisis:

a. Masalah utama yang akan dicari penyebabnya adalah proses order spare part yang lama, sehingga diwakilkan menjadi gambaran kepala ikan yaitu yang berada di ujung tulang utama (garis horizontal).

b. Pada setiap cabang terdapat faktor-faktor penyebab yang lebih rinci yaitu:

1) Manusia

a) Kurangnya pengalaman part man dalam mencari estimasi atau part number sesuai dengan tipe kendaraan, sehingga menimbulkan waktu proses yang cukup lama.

b) Kurangnya motivasi karyawan dalam melakukan tugasnya dikarenakan kurangnya reward yang diberikan perusahaan dan besarnya salary.

2) Metode kerja

a) Timbulnya proses pelayanan yang terlalu panjang dikarenakan adanya beberapa persetujuan dari beberapa manager yang harus dilalui saat proses order part dilakukan.

b) Terbatasnya waktu buka pembuatan PO yang ditentukan oleh ATPM, sehingga tidak bisa setiap hari melakukan proses order part.

c) Adanya keterlambatan proses input part ke dalam program service dalam bentuk IRIS dan DN sign in.

3) Lingkungan kerja

Dengan adanya proses persetujuan yang dilalui kepada beberapa manager, diperlukan persetujuan langsung berupa tanda tangan. Dengan adanya tahap ini, timbul waktu
e-ISSN 2657-0181

tambahan karena setiap manager memiliki jarak cukup jauh.

4) Material/ part

Untuk proses pemesanan part dibutuhkan syarat dengan minimal order pembelian, sehingga muncul kendala saat pemesanan part yang memiliki nilai beli kurang dari batas yang telah ditentukan, maka harus menunggu pemesanan part yang lainnya.

5) $\mathrm{Mesin} /$ peralatan

a) Kurangnya alat dalam proses scan untuk scanning PO yang dibuat.

b) Terjadinya kendala eror program EPC dalam proses estimasi part.

\section{IV.SIMPULAN}

Penelitian dilakukan mempunyai tujuan utama untuk mengoptimalkan proses pemesanan spare part yang dinilai memiliki proses dan waktu tunggu yang lama. Sehingga menimbulkan keluhan customer yang berakibat menurunnya unit entry dan peforma bengkel. Setelah dilakukan proses analisis dengan metode value stream mapping ditemukan beberapa waste yang menimbulkan over process. Kesimpulan dari penelitian ini adalah yang pertama waktu proses pemesanan spare part dapat dioptimalkan dengan cara eliminasi waste yang timbul dalam setiap tahapan proses pelayanan. Yang kedua, langkah awal yang dilakukan dalam meningkatkan efektifitas proses yaitu dengan cara identifikasi waste yang timbul. Dari hasil pengolahan data, diketahui bahwa waste dengan kategori over production sangat mempengaruhi timbulnya waste lain pada proses pelayanan. Yang ketiga, pelayanan proses order spare part dapat dimaksimalkan setelah dilakukan analisis dengan process activity mapping yang merupakan salah satu alat dari value stream analisys tools (VALSAT). Yang keempat, kepercayaan customer dan unit entry bengkel dapat ditingkatkan seiring meningkatnya optimasi proses pelayanan.

Hasil dari penelitian ini berupa usulan perbaikan terhadap proses pelayanan order spare part yaitu dengan minimasi proses persetujuan pemesanan, dengan cukup mendapat konfirmasi atau tanda tangan kepala bengkel. Tidak menunggu persetujuan lanjutan dari aftersales manager terlebih dahulu. Dengan demikian proses pemesanan part dapat segera 
dilakukan. Pada tahap proses pemesanan yaitu saat

penerimaan part, setelah dilakukan pemeriksaan kuantitas dan kualitas oleh partman, part yang diterima bisa langsung diinput ke dalam program service agar dapat segera diproses tanpa harus menunggu surat izin input dan IRIS. Memberikan masukan kepada ATPM untuk memberikan kebebasan hari dalam buka PO dan pembatasan minimla pembelian. Upgrade program service internal bengkel khusunya program Electronic Part Catalog (EPC) dalam proses estimasi part.

\section{DAFTAR PUSTAKA}

[1] C. Alexander, C. Wilson, \& D. Foley, (2014). 1,1 , 2. 33(3), 448-450.

[2] F. Alpasa, \& L. Fitria, (2014). Penerapan Konsep Lean Service Dan DMAIC Untuk Mengurangi Waktu Tunggu Pelayanan. Jurnal Online Institut Teknologi Nasional, 02(03), 10.

[3] U. Amrina, (2018). Modul Praktikum Perancangan Lean Manufacturing. Tangerang: Pustaka Mandiri.

[4] S. Assauri, (2016). Manajemen Operasi Produksi Pencapaian Sasaran Organisasi Berkesinambungan. Depok: PT Rajagrafindo Persada.

[5] S. Assauri, (2008). Manajemen Produksi dan Operasi. Jakarta: Lembaga Penerbit Fakultas Ekonomi Universitas Indonesia.

[6] S. E. Buffa, (1993). Manajemen Produksi/ Operasi. Jakarta: Erlangga.

[7] Daonil, (2012). Implementasi Lean Manufacturing Untuk Eliminasi Waste pada Lini Produksi Machining Chast Wheel Dengan Menggunakan Metode WAM dan VALSAT. (Tesis). Fakultas Teknik Program Studi Teknik Industri, Universitas Indonesia, Depok.

[8] Y. C. Fernando, (2014). Optimasi Lini Produksi Dengan Value Stream Mapping Dan Value Stream Analysis Tools. 125-133.

[9] R. Ginting, (2007). Sistem Produksi. Yogyakarta: Graha Ilmu.

[10] K. Halim, \& H. C. Palit, (2016). Perbaikan Proses Penerimaan Spare Part dengan Menghilangkan Peran Gudang Main Store : A Case Study. 4(2), 257264.

[11] M. Haming, \& M. Nurnajamuddin. (2017). Manajemen Produksi Modern Operasi Manufaktur dan Jasa. Jakarta: PT Bumi Aksara.

[12] J. Heizer, \& B. Render. (2009). Operation Management Edisi 9. Jakarta: Salemba Empat.

[13] M. P. Tampubolon, (2014). Manajemen Operasi dan Rantai Pemasok. Jakarta: Mitra Wacana Media.

[14] F. Tjiptono, \& A. Diana. (2003). Total Quality Management (TQM)-Edisi Revisi. Yogyakarta: Andi.

[15] H. C. Wahyuni, W. Sulistyowati, \& M. Khamrin. (2015). Pengendalian Kualitas; Aplikasi pada Industri Jasa dan Manufaktur dengan Lean, $6 S$ dan Servql. Yogyakarta: Graha Ilmu. 